November 17th. The button, or rather long plate, was removed; and all was found to be firmly united, except about an inch of the end of the urethra, arising from one shot having been knocked off by repeatedly passing the catheter. She was, however, able to hold all her urine during the day; and it was only when she was very soundly asleep at night that she lost any.

November 24 th. Three more silver sutures were put in, and a projecting notched plate applied, so as to close all the urethra, except the meatus itself.

December 4 th. The button was removed, and the parts were found all firmly united. She is able to retain her urine within the bladder for an hour at a time.

REMarks. This case is worth reporting as one of the most extensive fissures perhaps ever closed by a single operation, and as decisively showing the great advantages of Bozemann's plan of operation, which succeeded in closing a fissure four or five times as large as that which had been repeatedly operated on by the older methods without success. 'The complication introduced into the case by the division of the urethra caused it to present some resemblance to the cases we reported a short time since, in which the anterior portion of the urethra had suffered from the same injury which had produced the vesico-vaginal fistula.

\section{olitimal Communitations.}

\section{CASE OF TETANUS.}

By Ricinard Griffin, Esq., Weymouth. A heatthy man, aged 40, employed as a brewer, and occasionally a maltster, was digging potatoes; and, whilst so engaged, struck his great toe with a fork, which penetrated his boot, and caused blood to spirt from under the nail. The injury was not sufficient to prevent him from continuing his occupation; and in a day or two it was forgotten. On the ninth day from the receipt of the injury, he felt stiffness in his jaw, and inability to open his mouth sufficiently wide to eat. He, however, went to work as usual, and made up for the deprivation of solid food by drinking a sufficient quantity of beer during the day to make himself " muzzy", in which state he went to bed, and believes he slept all night. On rising in the morning, he became alarmed at the continued stiffness of his jaw, and walked three-quarters of a mile to his medical attendant, who prescribed for him ten grains of calomel to be taken immediately, and a saline with antimony every two hours; also a mustard poultice to be applied the entire length of the spine.

Two hours afterwards, I was requested to attend him. His pulse was then 80 , and moderately full. Under the nail of the injured toe there was some coagulated blood, but not the slightest tenderness there, nor in the foot, leg, or thigh. There was a slight abrasion of the skin over the tibia, occasioned the day before, whilst standing on a ladder to whitewash the brewery; but this occurred after the first accession of the attack. Ho was directed to go to bed, and continue the mixture, with the addition of a grain of calomel every two hours. During the day he was visited three times; and, with the ex. ception of profuse perspiration, which stood in drops on his face, and the pulse rising to 93, he continued apparently the same. In the evening, he was ordered a black dose, half of which only was taken by teaspoonfuls during the night, on account of his inability to swallow.

$\mathrm{He}$ is reported to have passed a quiet night, and appeared much the same as on the preceding day, excepting that he had been distressed by the secretion of viscid mucus, which collected in his pharynx, and impeded respiration: this he was continually attempting to eject from between his closed teeth. $\mathrm{He}$ was lying on his back, with his head elevated and drawn back, pillows being under the cervical and dorsal vertebre, and a chair under these, which gave the impression of a state of permanent opisthotonos. He was still perspiring profusely, drops standing on his face, and reappearing almost as soon as wiped away. On examining the spine, it was found to be reddened its entire length, and for four inches in width, by the mustard. To this discoloured surface the strong iodine paint was frecly applied. The nail of the injured toe was cut away, in case there should be any irritating substance under it; but I could discover no wound, nor anything to account for the symptoms. As the nail was undermined by coagulated blood, no pain was given, nor wound made; but, during the excision, a violent tetanic spasm occurred, which lasted ten minutes, and threatened every instant to terminate the patient's existenceso great was the difficulty of breathing, from constriction of the muscles and accumulation of viscid mucus in his throat, which he endeavoured to eject from between his closed teeth every few seconds.

At a consultation of four medical men, it was decided to make a blister over the cervical vertebræ, and to insure a rapid action, the strong solution of ammonia was used; the cuticlo was then removed, and the surface was sprinkled with five grains of acetate of morphia. An enema of gruel, salt, and four ounces of spirit of turpentine, was then administered, as the bowels had not been relieved, although two doses of croton oil had been given, at intervals of two and three hours.

For the purpose of applying the ammonia, he was placed on his side, in which position he continued until his death, as it permitted the mucus to escape more readily, and thereby rendered the respiration easier.

To facilitate the application of remedies to his back, his shirt was rent through its entire length, which enabled us to see the state of the spine from time to time. The dark mahogany stain of the iodine paint entirely disappeared one hour after its application, not even a lemon tint remaining; his shirt was also unstained, showing that the profuse perspiration in which he was bathed had the effect of chemically decomposing it. Turmeric paper applied to the skin was unaltered, but litmus was slightly reddened. Immediately after the second application of the iodine, and before the clothes were placed over him, a violent spasm supervened; it commenced with his shrieking out "Oh! oh!", and throwing himself violently on his face. The contraction of the muscles was most rigid; the abdominal were as hard as boards; the facial were distorted ; the angles of the mouth were drawn as far as possible towards the ears; the lips were compressed; the complexion purple; the legs stretched out straight; the arms flaccid; the hands clenched; the respiration was rapid, with forcible and difficult ejection of saliva from between his closed teeth at each expiration; the eyes were turned upwards, the lower part of the whites alone being visible, excepting when the lids were elevated by the fingers, when the iris was seen to be contracted; pulse 216 , almost countless. Death appeared imminent, as the respiration was most difficult. The spinal column was not bowed, as is generally supposed. The head, with the cervical vertebræ, were drawn forcibly backwards; these forming a considerable angle with the dorsal, which were perfectly straight, as were also the lumbar. The pelvis was, however, forced backwards as far as it was possible; the sacrum, like the cervical vertebris, forming a considerable angle with the lumbar, giving the man, as far as the lower part was concerned, the appearance of a Hottentot. Had the man been placed on a flat surface, the upper part of the occipital bone and the coccyx would alone have touched it, the heels being slightly raised above it. After the spasm had ceased, I placed a stick lengthwise of his back, one end resting on the occiput, and the other on the sacrum; and I found the interspace between it and the lower part of the dorsal vertebræ nearly four inches. The anglo during the fit did not greatly exceed this: the spasmodic contraction of the muscles behind was, therefore, nearly permanent. This spasm was less severe and of shorter duration than the former one, arising probably from his having inhaled chloroform at short intervals during the last hour, and during the greater part of the time the fit was on, though occasionally it was thrust from it. The inhalation was continued, with short intermissions, until he expired. One ounce und a half of chloroform was consumed, but probably not half of it inhaled. The enema acted slightly about an hour after its injection, and again at an interval of an hour; the motions being slightly relaxed, and displaying no unusual appearance; but the bowels were far from being emptied, as some of their contents, of tolerable consistence, escaped after his death. His urinc, which was scanty and viscid, was passed only once in twenty hours. From the time of his second spasm until his death, he called out every few minutes, "Oh!"; and at the same timo suffered from a sudden spasmodic jerk backwards, but almost inmediately relaxed into a tranquil state, occasionally snoring, and evidertly being under the influence of the morphia and chloroform. The pulse varied during the day from 160 to $216 ;$ the respiration was 22 ; the external jugulars were distended the face and hands were blueish. 
After the second fit, I procured some tincture of Indian hemp, thirty drops of which, with a small quantity of water, was with difficulty swallowed; but no more was taken, as he was unable to get it down.

On my fifth visit to him that day, he was seized with his third severe spasm, the first having occurred eight hours previously. The attack was of short duration. The pulse, which at its commencement was readily felt, gradually became indistinct, and the respirations gasping; and it would be difficult to say which terminated first, had not a slight gasp occurred a few seconds after I believed he was dead. During the last fit, the muscles of the face were relaxed; the thighs and legs flexed, but motionless; the arms bent; the hands clenched. Immediately after death, his countenance resumed a quiet aspect.

The next morning, I examined the body externally, and observed that the face was mottled, and showed signs of rapid decomposition. The legs were straight, and the back without any bend in it; the fingers were clenched, but easily opened. An anatomical inspection was refused, until some relations at a distance could be consulted : the body was then too far advanced in decomposition to render an inspection satisfactory; indeed, it was obliged to be buried forty hours after death.

\section{ON AMPUTATIONS.}

Jiy John Russeld, Esq., Merthyr Tydfil.

IN hazarding suggestions respecting the common operation of amputation, I fully expect to have been anticipated in my ideas, as practice would be likely to give rise to them with others as well as with myself. My object is to draw the attention of the more inexperienced in this branch of surgery to the very great difference between amputation performed on one limb shrunken from disease and inaction, and on another in a state of health and development. I have searched the most recent and high works of authority on operative surgery, with the expectation of finding the point touched upon; but I have not succeeded.

A young operator, whose only experience has been on"the dead subject, should he be called upon to operate upon a limb in the first condition above deseribed, would find an absence of all elasticity of skin, cellular tissue, and muscle; and he would find no unequal retraction of parts, and probably no natural separation or retraction of them : and, should he have followed strictly the directions laid down by authorities, he would find the result correspond with his previous practice on the dead subject, and his operation would necessarily be followed by a flattering stump.

But, in the case of a limb in the opposite condition, he would find circumstances very different, and be very likely disappointed at the result; as, in such a case, all structures would be found in the highest degree elastic, and the retraction of them very unequal. The skin would retract most, and the muscles (each layer) less and less towards the centre of the limb, thereby causing somewhat of a convex instead of a concave flap.

'The contrast between these two conditions has appeared to me so striking, that it surprises me so little notice has been taken of it. I have looked through Liston's, Skey's, and Erichsen's works on operative surgery, for suggestions applying to the different cases; but the only one bearing upon the point is the plan proposed by Mr. Skey in amputations (I believe?) in general : viz., that of pressing up the muscles under the protection of the bone with the flat hand before transfixing, preparatory to making the posterior flap. I have not tried this plan. It appears to me, however, that, in so doing, the surgeon must sacrifice skin as well as muscle, although not in the ordinary proportions. And I fear that the palm of the hand, and more especially the ball of the thumb, must be inconveniently near the knife.

My own plan has been to make two lateral incisions through the skin; then to grasp a fold of it between the finger and thumb (similar to the fold seized when lifting a dog by the nape of the neck), before transfixing for the posterior flap; and to carry the hand down, keeping pace with the knife, until sufficient flap has been secured; then to cut out. By this plan there is great gain of integument, and sacrifice of useless muscle; and the operator's hand is safely out of the way of the knife. The sacrifice of muscle will be found of great advantage; and the limb should be transfixed close to the margins of the drawn skin. It is hardly possible to save too much skin; for, however bag-like and unseemly it may look at the time, it will eventually contract to the dimensions of the stump. The occasional difficulty of securing the vessels, after amputation of the leg, suggests the plan of carefully passing the knife perpendicularly and square to the plane of the bones, a short distance below the intended site of sawing through them, and then cutting up a short way close to each; thus leaving a tongue of muscle and ligament between the bones which would contain the vessels.

I see mention is made, in the Journal of November 13th, of the use of silver sutures in King's College Hospital, as imported from America. In reference to this, I beg to say that, in 1835, as dresser at Guy's Hospital, I assisted the late $\mathbf{M r}$. Morgan in a case of amputation of the leg, in which he used silver sutures. As if to test their utility, secondary hæmorrhage came on in the evening. But the pain caused by the angles of the untwisted wire seemed to be an objection to its use. Besides this, the wire across the wound very much interfered with the search for the bleeding vessel. Wire may, nevertheless, be found useful in other cases.

A point much overlooked in operative surgery is the use of warm instruments. Of this I had a striking illustration the other day. A patient had a bubo opened by a cold lancet. A short time afterwards, another abscess formed, and discharged its contents by forming a communication with the first opening, which was about an inch and a half distant. I slit open the canal of communication, having carefully warmed the director and bistoury. The patient ridiculed the dread which he had entertained previously to the operation: he said that the pain was trifling, compared with the former operation of lancing and immediately assigned the reason himself. The practice of warming tooth instruments is very common, and is a great comfort to patients.

\section{ANALYSIS OF FIVE HUNDRED CASES OF L A B O U R.}

By Fredertck Coliriss, M.D., Wanstead.

Complyivg with the hint given in the Journal of November 27 th, I have pleasure in forwarding an analysis of the midwifery cases I have attended within the last few years.

Number of cases . $\quad . \quad \cdot \quad \cdot \quad \cdot \quad \cdot \quad$ • 500

Twin cases . $\quad . \quad \cdot \quad \cdot \quad \cdot \quad \cdot \quad \cdot \quad 8$

Total number of children $\left\{\begin{array}{ll}\text { Males } & 280 \\ \text { Females } & 228\end{array}\right\} 508$

Presentations :-

Natural (the membranes being expelled entire) in 4 cases)

Face towards pubes

Breech.

Foot-including 4 cases of turning

Arm

Still-born :-

Putrid .

Premature

Craniotomy

Other cases

\section{8}

Funis round the neck: in several cases three times Placenta partially presented . $\quad . \quad . \quad . \quad . \quad . \quad 2$ Placenta adherent: in one instance extremely ossified

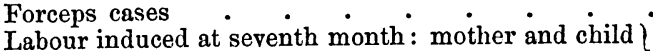
did well .

Acephalous foetus.

Six fingers and toes on each hand and foot: said to

be hereditary on the male side . . . Slight post partum hæmorrhage . $\cdot 5 \cdot \quad \cdot \quad \cdot 9$

Mothers died from causes unconnected with labour:On fourth day, from disease of the heart with anasarca.

A few hours after delivery, from cholera : . On twelfth day, from confluent small-pox :

Three hours after labour, from inanition : not from hæmorrhage, but caused by insufficiert nourishment during pregnancy. This was her twelfth labour . 